\title{
Comparison of Thermogenic Effect between Meals Containing Protein Predominantly from Animal and Plant Sources
}

\author{
A. Fahmy Arif Tsani, Myung-Hee Kim, and Eun-Kyung Kim
}

\begin{abstract}
Recently there are many efforts to increase thermic effect of food (TEF) by changing nutrient sources, which may be relevant for weight loss program. The aim of this study was to compare the thermic effects of different protein sources, animal and plant protein diet, on postprandial energy expenditures (PEE). Seven healthy female university students (mean age 22.3 $\pm 0.5 \mathrm{yrs}$ ) participated in two isoenergetic meal ingestions. Animal and plant protein diet were represented by breast chicken and tofu meal, respectively. Each meal provided $15 \%$ of individual energy need, which were composed of $22 / 18 / 60 \%$ as protein/fat/carbohydrates. Resting energy expenditure were measured in pre- and post-prandial state (every 30-min during 4 hours) using an indirect calorimetry. There were no significant differences in PEE between chicken and tofu meal. PEE of chicken meal group increased more rapidly (peak at $30 \mathrm{~min}$ ) than those of tofu meal (peak at 120 min). However, PEE of tofu meal decreased relatively faster after peak time. Total thermogenesis of animal protein diet was $16.8 \mathrm{kcal} / 4 \mathrm{~h}$, higher than plant protein diet's $(13.7 \mathrm{kcal} / 4 \mathrm{~h})$, but not significantly different. $8.68 \%$ of energy intake in animal protein diet and $6.94 \%$ in plant protein diet were oxidized as thermic effects for the digestion and absorption of the diets. Further studies that using higher energy content and protein composition in test meals should be continued to find the adequate protein source for increasing TEF.
\end{abstract}

Index Terms-Female adult, indirect calorimetry, protein, thermic effect of food.

\section{INTRODUCTION}

Obesity has become one of the primary health concerns in the world since its prevalence increased dramatically. The increase in prevalence of the associated comorbidities is a significant burden of health care system worldwide [1]. Increase in energy intake and decrease in energy output are claimed as two main causes of the development of positive energy balance, which related to obesity [2]. Thermic effect of food (TEF) is one among the contributors to energy output, besides energy used for basal metabolism, physical activity, and non-exercise activity thermogenesis (NEAT) [3]. TEF is

Manuscript received August 6, 2012; revised September 15, 2012. This work was supported by Basic Science Research Program through the National Research Foundation of Korea (NRF) funded by the Ministry of Education and Technology Republic of Korea (2011-0005899)

A. F. A. Tsani is with the School of Health Nutrition, Faculty of Medicine, Universitas Gadjah Mada Yogyakarta 55281, Indonesia. Currently as postgraduate student of Food and Nutrition Department, Gangneung-Wonju National University, Kangwon-do 210-702 South Korea (e-mail: fahmi_tsani@yahoo.com).

M. H. Kim and E. K. Kim are with the Food and Nutrition Department, Gangneung-Wonju National University, Kangwon-do 210-702 South Korea (e-mail: milimhol@hanmail.net, ekkim@gwnu.ac.kr). the increase in energy expenditure above resting, which required for digestion and absorption of ingested food. It is the major form of thermogenesis in humans, accounting for $5 \%$ to $15 \%$ of the total daily energy expenditure [4].

A number of findings suggest that the TEF of separate nutrients is higher for protein than other macronutrients [5]. It has been speculated that different protein sources may affect TEF differently [6], but only very limited data from human studies on this topic is available. Considering the possible effects of protein source, the present study aimed to compare the thermogenic effects between meals containing protein predominantly from animal and plant sources on postprandial energy expenditures (PEE). We hypothesize that compared to the plant based diet, the use of meals with predominantly protein from animal-based may stimulate energy expenditure.

\section{SUBJECTS AND MATERIALS}

\section{A. Subjects}

Seven healthy female university students participated in the study. Characteristics of the subjects are shown in Table I. Subjects were recruited by Department of Food and Nutrition, Gangneung Wonju National University (GWNU). The inclusion criteria were if they informed no more than moderate physical activity and were not suffering from chronic disease including diabetes, heart disease, hypothyroidism, and fat metabolism disorders. Females were not pregnant and were excluded if they were smoker. They were asked not to change their regular lifestyle and physical activity levels during test days. They were fully informed about the procedures of this study and informed consent was obtained from each subject. This study was approved by GWNU prior to implementation.

\section{B. Study Design}

Two different isocaloric breakfast meals including animal and plant protein based diet were tested in a randomized crossover design. After an overnight fasting at least 8 hours and minimal amount of activity, the subjects were randomly assigned to the sequence of test meals. There was a washout period of $>5$ days between test days, and each test day lasted $5 \mathrm{~h}$.

On the morning of the test days, the subject travelled to the Department of Food and Nutrition by car, bus, or slowly walking, to arrive at 8.30 a.m. After reach the laboratory, the anthropometry of the subjects were measured. Fasting energy expenditure were measured for $15 \mathrm{~min}$ after $10 \mathrm{~min}$ rest in 
bed. Then, the subjects were instructed to consume the test meal within 15 min. Respiratory exchange measurements were used to estimate energy expenditure at baseline (resting energy expenditure: REE).

TABLE I: CHARACTERISTICS OF SUBJECTS

\begin{tabular}{|c|c|c|c|}
\hline \multicolumn{4}{|c|}{$\begin{array}{l}\text { Healthy female adults } \\
\qquad(\mathrm{n}=7)\end{array}$} \\
\hline Age (years) & 22.3 & \pm & 0.5 \\
\hline Height $(\mathrm{cm})$ & 162.7 & \pm & 5.6 \\
\hline Weight (kg) & 51.5 & \pm & 9 \\
\hline Body mass index $\left(\mathrm{kg} / \mathrm{m}^{2}\right)$ & 19.3 & \pm & 2.2 \\
\hline Waist-hip ratio & 0.76 & \pm & 0 \\
\hline Fat mass (kg) & 13.9 & \pm & 4 \\
\hline Fat mass (\%) & 26.6 & \pm & 5 \\
\hline Muscle mass (kg) & 20.6 & \pm & 3.7 \\
\hline
\end{tabular}

TABLE II: COMPOSITION OF THE INTERVENTION DIETS

\begin{tabular}{lccc}
\hline \hline & Chicken & Tofu & Significance \\
\hline Energy intake & $15 \%$ RMR & $15 \%$ RMR & NS $^{1)}$ \\
\hline$\%$ energy as macronutrient & & \\
\hline Carbohydrate & $59.90 \%$ & $60.80 \%$ & NS \\
Protein & $22.20 \%$ & $21.70 \%$ & NS \\
Fat & $17.90 \%$ & $17.50 \%$ & NS \\
\hline \hline
\end{tabular}

Not Significant

\section{Test Meal}

The two interventions consisted of meals with different compositions and varied in protein source. Animal protein diet was represented by breast chicken meal and plant protein diet was represented by tofu meal. Each meal was calculated to have the same energy (isoenergetic). Both of them were cooked and served with rice and kimchi as Korean breakfast style. Each meal provided $15 \%$ of each individual energy need, which was determined by weight, height, and age. Table II describes portion of meal, which composed nearly of $60 \%, 22 \%$, and $18 \%$ energy as carbohydrate, protein, and fat, respectively. This macronutrient composition followed standard menu in Korean population [7]. Meals were prepared at Culinary Laboratory at Department of Food and Nutrition, GWNU. Food ingredients were weighed to the nearest $0.1 \mathrm{~g}$. Analysis of the macronutrient of the meal was performed using the computerized nutrient composition program Computer Aided Nutritional Analysis Program Version 3.0 (CAN Pro 3.0).

\section{Anthropometry}

Anthropometric measurements were carried out by the same investigator. The data included weight, height, body mass index, and body composition. Weight and height were measured using a digital scale and stadiometer. Weight was obtained with the subject in light clothing and measured to the nearest $0.1 \mathrm{~kg}$. Height was measured to the nearest $0.1 \mathrm{~cm}$ without shoes and socks. Body fat and skeletal muscle were measured by bioelectrical impedance analysis (Inbody720, Biospace Corp., Korea). Waist-hip ratio was collected by measurement using tap line.

\section{E. Gas Exchange Measurements}

Measurements of fasting and 4-h postprandial energy expenditure were conducted with indirect calorimetry of a TrueOne 2400 metabolic cart (Model QMC, ParvoMedics Corp., USA), which recorded the amount of $\mathrm{O}_{2}$ consumed and $\mathrm{CO}_{2}$ produced. The ventilated hood system was automatically recalibrated every five minutes during measurement.

Upon arrival to the laboratory, subjects were asked to relax for 10 minutes before measurement. The REE was measured for 15 minutes before consumption of each meal. The postprandial energy expenditure during 4 hours were measured every 30 minutes (15 min measured time and 15 min break time). No additional foods were permitted for the following 4 hour. For all measurements, subjects remained in a supine position in an adjustable bed with their head placed under a transparent ventilated hood connected to monitor by tube. In order to keep in drowsiness, documentary video was provided that can be quietly watched by subjects.

The REE represents an average of the full collection period and was calculated from the oxygen consumption and carbon dioxide production by using the Weir equation [8]. The thermogenic effect (TEF) of test meals was calculated as the difference of the postprandial and the fasting energy expenditure [9].

\section{F. Data Analysis}

Data were analyzed using the Statistical Analysis System (version 9.2, SAS Institute Inc, Cary, NC). Paired t-test was used to compare postprandial energy expenditure between chicken and tofu meal. This analysis was also used to compare preprandial and postprandial energy expenditure in both meals. Area under curve (AUC) analysis were applied to calculate how much the total amount of TEF during 4 hours measurement.

\section{RESUlTS AND DISCUSSION}

Seven subjects participated and completed the study. All data concerning anthropometric measurements are summarized in Table I. Mean age and BMI are 22.3 \pm 0.5 years and $19.3 \pm 2.2 \mathrm{~kg} / \mathrm{m}^{2}$, respectively.

In the present study, we compared animal protein diet (chicken) and plant protein diet (tofu) to measure effects on energy expenditure. Studies of human energy metabolism consistently report higher energy expenditure following consumption of high protein meals [10]. It may be that the body has no storage capacity to cope with high intakes of protein and therefore has to process it metabolically, which increases thermogenesis [11]. 
TABLE III: PREPRANDIAL AND POSTPRANDIAL ENERGY EXPENDITURE OF SUBJECTS (UNIT: KCAL/DAY)

\begin{tabular}{lcccccc}
\hline \hline & $\begin{array}{c}\text { Chicken meal } \\
\text { (animal based) }\end{array}$ & $\begin{array}{c}\text { Tofu meal } \\
\text { (plant based) }\end{array}$ & $\begin{array}{c}\text { Difference } \\
\text { (chicken-tof } \\
\text { u) }\end{array}$ \\
\hline Preprandial state & $1251 \quad \pm 225$ & 1250 & \pm 200.1 & $0.7^{\mathrm{NS}}$ \\
Postprandial state & & & & & & \\
$30 \mathrm{~min}$ & 1392.6 & $\pm 266.2^{* * 1)}$ & 1355 & $\pm 234.5^{*}$ & $37.9^{\mathrm{NS}}$ \\
$60 \mathrm{~min}$ & 1376.1 & $\pm 228.5^{* *}$ & $1361 \quad \pm 246.9^{*}$ & $15.0^{\mathrm{NS}}$ \\
$90 \mathrm{~min}$ & 1352.9 & $\pm 241.2^{*}$ & $1351 \quad \pm 242.4^{*}$ & $2.4^{\mathrm{NS}}$ \\
$120 \mathrm{~min}$ & 1371.4 & $\pm 257.5^{* *}$ & $1370 \quad \pm 218.6^{* *}$ & $1.3^{\mathrm{NS}}$ \\
$150 \mathrm{~min}$ & 1327.5 & $\pm 258^{*}$ & $1312 \quad \pm 235^{*}$ & $15.5^{\mathrm{NS}}$ \\
$180 \mathrm{~min}$ & 1331.4 & $\pm 254.4^{* *}$ & $1304 \quad \pm 212.5^{*}$ & $26.6^{\mathrm{NS}}$ \\
$210 \mathrm{~min}$ & 1348.6 & $\pm 266.4^{*}$ & $1324 \quad \pm 233.4^{*}$ & $24.9^{\mathrm{NS}}$ \\
$240 \mathrm{~min}$ & 1321.7 & $\pm 231.2^{* *}$ & 1299 & $\pm 1298.6^{*}$ & $14.1^{\mathrm{NS}}$ \\
\hline \hline
\end{tabular}

1) Significantly different by Paired t-test between preprandial and postprandial state

$*: \mathrm{p}<0.05 ; * *: \mathrm{p}<0.01$

2) Not significant between chicken and tofu meal

The preprandial and postprandial energy expenditures are shown in Table III. Paired t-test analysis shows that energy expenditure increased significantly after meal consumption during 4 hours measurement in both animal and plant protein diets. However the preprandial and postprandial energy expenditure are similar between two diet interventions. The increased energy expenditure associated with the consumption of a meal. The degree to which metabolism increases after meal consumption is strongly related to the energy content [5]. In this study, the energy content of the meal was $15 \%$ of the subject's daily energy need. It can be the answer why only small value of energy expenditure increased in postprandial state, which were 61.6 141.5 $\mathrm{kcal} /$ day and 48.2 119.6 kcal/day for chicken and tofu meal, respectively (data not shown).

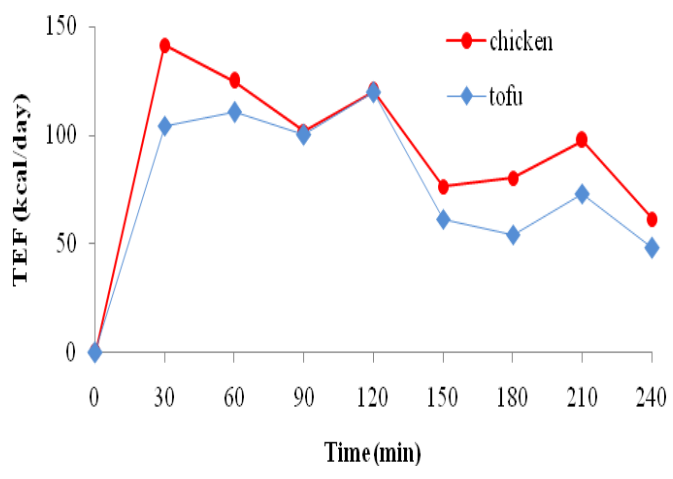

Fig. 1. TEF curve at each 30-min over 4 hours after meal

The thermic effect of both meals, which was the increased energy expenditure, are expressed in Fig. 1. Chicken meal reached the peak as soon after ingestion (at $30 \mathrm{~min}$ ). The peak of tofu meal was reached more late (at $120 \mathrm{~min}$ ). TEF after chicken meal typically laid above those after tofu meal ingestion during 4 hours measurement. Exploration using Area Under Curve (AUC) analysis demonstrated that total thermogenesis of animal protein diet was $16.8 \mathrm{kcal}$, higher (not significant) than $13.7 \mathrm{kcal}$ of tofu meal's (Fig. 2).

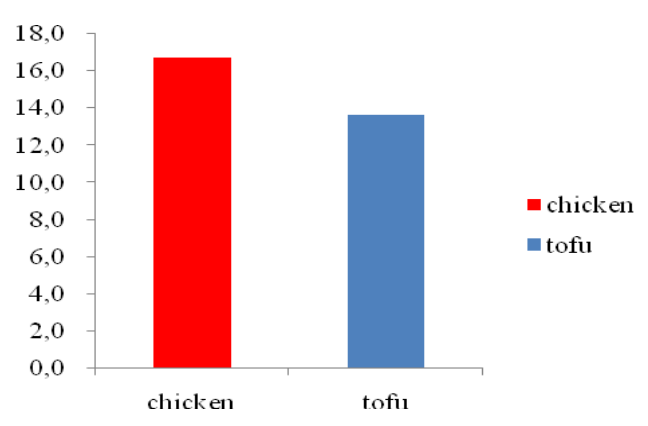

Fig. 2. Total of TEF over 4 hours postprandial (unit: kcal).

This result was probably due to lower composition of protein in the meal as standard menu. Similarly with present study, Tan et al [12] observed that during 8 hours stay in respiratory chamber, total PEE was slightly higher in participants who were served meals containing meat as the main protein source than those who received soy protein meals, but not significant. Other study reported that the animal protein diet produced a greater increase in total PEE than plant protein diet, which suggest different source of meals may invoke different thermogenesis response [13]. They used pork and tofu as animal and plant protein based diet in higher composition $(29 \%)$, whereas in this present study composition of protein was only $22 \%$.

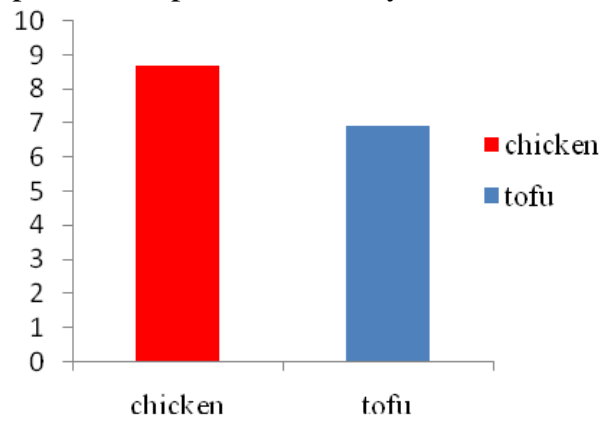

Fig. 3. Percentage of energy intake as TEF (unit: \%).

Fig. 3 describe the ratio of thermic effect both of meals and energy intake. $8.68 \%$ of energy intake in chicken diet and $6.94 \%$ in tofu diet were oxidized as thermic effect. In line 
with this result, Schutz et al [4] observed that 5-15\% of total daily energy expenditure is typically accounted from diet induced thermogenesis. Other study also reported that among macronutrients, protein has a higher thermic effect than carbohydrate and fat [14]. The percentage of energy intake was low in this study due to the macronutrient composition followed to standard menu (not high in protein). On the other hand, the measurement of postprandial energy expenditure was only during 4 hours. The thermogenesis process may still continue after 4 hours. It can be confirmed that at last minutes the TEF of chicken and tofu meal were $61.6 \mathrm{kcal} / \mathrm{day}$ and $48.2 \mathrm{kcal} /$ day, respectively.

The strength of our study is well-controlled measurements of anthropometric variable and resting metabolic rate. The limitation is we did not control for the pattern of menstruation in subjects, which may influence the metabolism.

\section{CONCLUSION}

In conclusion, we suggest that in the standard composition of protein in meals, postprandial thermogenesis seems to be similar between meals containing protein predominantly from animal and plant sources. Hence, we prompt to explore the further studies related to this finding. A longer measurement period with higher calorie amount and higher protein composition in the diet can be the alternative to get valuable thermic effect, which may be relevant for weight loss program.

\section{ACKNOWLEDGMENT}

Grateful acknowledgment is made for the facilities provided by Gangneung-Wonju National University under Department of Food and Nutrition. The authors would also like to thank the students and investigators for their participation in this study.

\section{REFERENCES}

[1] B. A. Swinbur, I. Caterson, J. C. Seidell, and W. P. James, "Diet, nutrition, and the prevention of exces weight gain and obesity," Public Health Nutr., vol. 7, pp. 123-146, Feb 2004.

[2] World Health Organzation Consultation on Obesity, Obesity-Preventing and Managing the Global Epidemic. Geneva: WHO, 1998.

[3] W. J. Schiff, Nutrition for Healthy Living. McGraw-Hill, 2009.

[4] Y. Schutz, T. Bessard, and E. Jequer, "Diet-induced thermogenesis measured over a whole day in obese and nonobese women," Am J Clin Nutr., vol. 40, pp. 545-552, Sept 1984.

[5] D. P. Jones, E. Westman, R. D. Mattes, R. R. Wolfe, A. Astrup, and M. W. Plantenga, "Protein, weight management, and satiety," Am J Clin Nutr., vo. 87 , pp. $1558-1561,2008$

[6] W. L Hall, S. J. L. Millward, and L. M. Morgan. "Casein and whey exert different effects on plasma amino acid profiles, gastrointestinal hormone secretion, and appetite," Br J Nutr., vol. 89, pp. 239-248, Feb. 2003.

[7] Korean Nutrition Society, Dietary Reference Intakes for Korean Kookjin Publishing Co, 2005.

[8] J. D. V. Weir JDV, "New methods for calculating metabolic rate with special reference to protein metabolism," J Physiol., vol. 109, pp. 1-9, 1949.

[9] E. Ravussin and B. A. Swinburn, "Energy expenditure and obesity," Diabetes Rev., vol. 4, pp. 403-422, 1996.

[10] T. L. Halton and F. B. Hu FB, "The effects of high protein diets on thermogenesis, satiety and weight loss: a critical review," J Am Coll Nutr., vol. 23, pp. 373-385, 2004

[11] N. J. Rothwell and M. J. Stock, "Effect of environmental temperature on energy balance and thermogenesis in rats fed normal or low protein diets," J Nutr., vol. 110, pp. 532-542, 1980.

[12] S. Y. Tan, M. Batterham, and L. Tapsell, "Energy expenditure does not differ, but protein oxidation rates appear lower in meals containing predominantly meat versus soy sources of protein," Obes Facts., vol. 3, no. 2, pp. 101-104, April 2010.

[13] P. B. Mikkelsen, S. Toubro, and A. Astrup, "Effect of fat-reduced diets on 24-h energy expenditure: comparisons between animal protein, vegetable protein, and carbohydrate," Am J Clin Nutr., vol. 72, pp. 1135-1141, Nov. 2000

[14] H. Karst, J. Steiniger, R. Noack, and H. D. Steglich, "Diet-induced thermogenesis in man: thermic effects of single proteins, carbohydrates, and fats depending on their energy amount," Ann Nutr Metab., vol. 28, pp. 245-252, 1984 